\title{
APPLICATION OF PASSIVE REMOTE SENSING TO INVESTIGATE TRANSMISSIVITIES OF TREES CANOPIES USING GROUND-BASED UPWARD-LOOKING MICROWAVE RADIOMETERS
}

\author{
Doan Minh Chung ${ }^{1}$, K. G. Kostov², Vo Thi Lan Anh', Huynh Xuan Quang ${ }^{1}$, \\ Tran Tuan $\mathrm{Anh}^{3}$, Mai Thi Hong Nguyen ${ }^{1, *}$, Le Dai Ngoc ${ }^{3}$ \\ ${ }^{1}$ Space Technology Institute, Vietnam Academy of Science and Technology, \\ 18 Hoang Quoc Viet, Cau Giay, Ha Noi, Viet Nam \\ ${ }^{2}$ Institute of Electronics, Bulgarian Academy of Sciences, \\ 72 Tzarigradsko chause- Sofia1784, Bulgaria \\ ${ }^{3}$ Defense Mapping Agency of VietNam, Ministry of Defence, 2/198 Tran Cung, \\ Co Nhue, Tu Liem, Ha Noi, Viet Nam \\ *Email: mthnguyen@sti.vast.vn
}

Received: 10 October 2016; Accepted for publication: 13 May 2017

\begin{abstract}
In Vietnam, in recent years, remote sensing technology has developed very strongly in many different application areas. Besides, remote sensing using optical satellite, radar satellites, passive remote sensing includingmicrowave radiometers has been studied for a long time.

This paper presents the results of the study on emission and transmissivity of trees canopyusing ground-based upward-looking microwave radiometers at two bands, $\mathrm{L}$ and $\mathrm{X}$ which were manufactured and calibrated byour research group at the Space Technology Institute Vietnam Academy of Science and Technology. In the field measurement campaigns in 2015 and 2016, brightness temperatures were calculated from the output signal of the radiometers that measure trees canopy, transmissivity of the canopy in L-band, and X-band was calculated from the physical temperature of the canopy,the brightness temperature of blue sky and the brightness temperature of the canopy after the radiometers were calibrated using blue sky and the black body at the corresponding frequency base on transmissivity model.

These results provide empirical evidence to quantify the characteristics of microwave which is transmitted in the canopy to support the analysis and assessment of corresponding data obtained when the device is set high above and measuring downwards to the canopy.
\end{abstract}

Keywords: ultrahigh frequency spectrometer, passive remote sensing, transmittivity.

\section{INTRODUCTION}

Remote sensing of forest canopies from airborne and spaceborne platforms using active and passive microwave systems is an advanced tool for ecosystem monitoring. Microwave 
radiometers could give additional information about denseforest transmissivity and biomass, where other remote sensing systems (opticalradiometers, Synthetic-aperture radar - SAR) suffer the early saturation effect. Ground-based upward-looking radiometers have been applied previously for monitoring the temporal changes of the emission of deciduous and coniferous trees, and estimating the corresponding transmissivity and foliar biomass from the radiometric data.

In remote sensing, the temperature and emission values are important parameters. Emission is related to temperature and transmission through foliage. Radiation from the trees can be partly absorbed and partially down to the ground. Although it is difficult to determine the emission from the transmissivity, it still affects to the microwave radiation from the canopy. The transmissivity of the vegetation contributes to determining the observed radiation. Transmissivity is one of the useful parameters for evaluating tree parameters.

The results of some studies on seasonal variations of emissivity measured by ground-based upward-looking radiometers have been reported to be rather homogeneous. Recently, Mätzler [1] studied the microwave transmissivities of a large oak tree (Fagus silvatica L.) over a frequency range of $1 \mathrm{GHz}$ to $100 \mathrm{GHz}$ using ground-based upward-looking radiometers. Experiments showed that short wave radiation is sensitive to plant parameters. The purpose of this paper is to investigate the emissivity, transmissivity of trees canopies using ground-based upward-looking microwave radiometersat L-band (center frequency of $1.4 \mathrm{GHz}$ ) and X-band (center frequency of $11 \mathrm{GHz}$ ).

\section{METHODOLOGY}

\subsection{Experimental description}

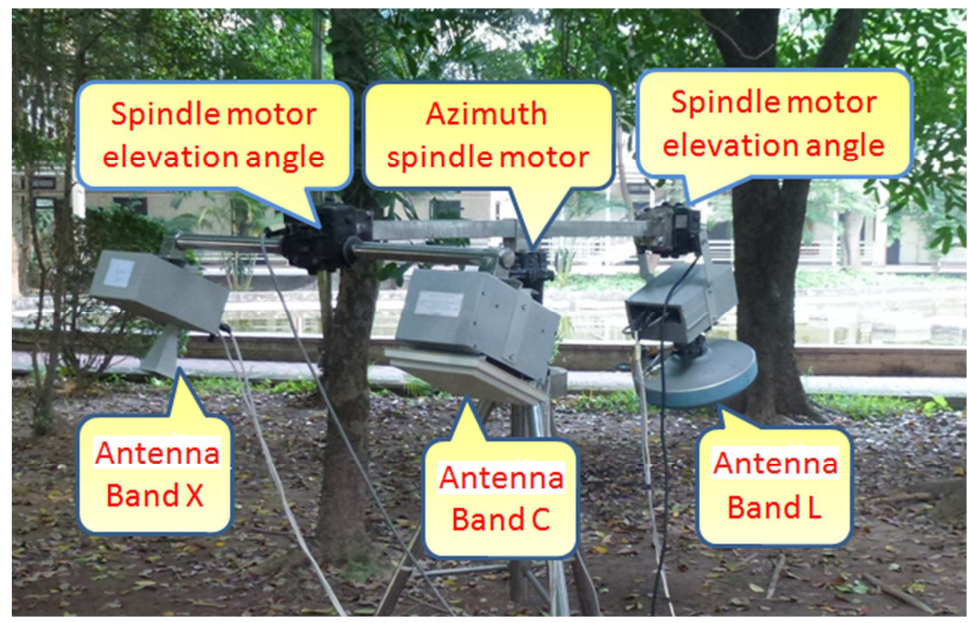

Figure 1. Three microwave radiometers mounted on a mechanical support.

Three microwave radiometers, namely the L-band radiometer LNIR, the C-band radiometer $\mathrm{CRM}$ and the X-band radiometer XRM were used for measuring the microwave emission of the objects under investigation. The microwave units and the antennas of the radiometers LNIR, CRM and XRM were mounted on a mechanical support with antenna angle positioning system (Figure 1). 
The LNIR is a Dicke-type noise-injection radiometer with center frequency $1.41 \mathrm{GHz}$. The $\mathrm{CRM}$ is a total-power radiometer with center frequency tunable in the range 3.5 to $3.7 \mathrm{GHz}$. The XRM is a Dicke-type radiometer with center frequency tunable in the range 10.95 to $11.25 \mathrm{GHz}$. The antenna beamwidths (at $-3 \mathrm{~dB}$ ) of the LNIR, CRM and XRM are $32^{\circ}, 15^{\circ}$ and $17^{\circ}$, respectively. All three radiometers have resolution (sensitivity) $\leq 0.3 \mathrm{~K}$ with one second integration time.

The radiometers have two measurement modes: LOCAL and REMOTE. When working in LOCAL mode, each radiometer calculates the average value of the output frequency and the variance for any measuring interval between 1 second and 1024 seconds. When working in REMOTE mode, the radiometer should be connected to a personal computer (via the RS 232 output port) for data recording and post-processing.

The joint field experiment was carried out in 2015 and 2016 near the Space Technology Institute, VAST campus in Hanoi, Vietnam (18 Hoàng Quốc Việt, coordinates 21 $02^{\prime} 48.3^{\prime \prime} \mathrm{N}$, $105^{\circ} 48^{\prime} 03.6^{\prime \prime} \mathrm{E}$ and altitude of 13 meters above sea level). A group of several African mahogany trees (Khaya senegalensis) was selected for this experiment. An infrared thermometer Fluke 63 and an electronic thermometer were used for measuring the temperatures of different tree elements, the temperature of the soil below the trees, the air temperature below the trees, and the temperature of the microwave absorber used for calibration of the radiometers. Before measuring the brightness temperature of an object or the environment, the microwave radiometers should be calibrated.

\section{Calibration of the microwave radiometers}

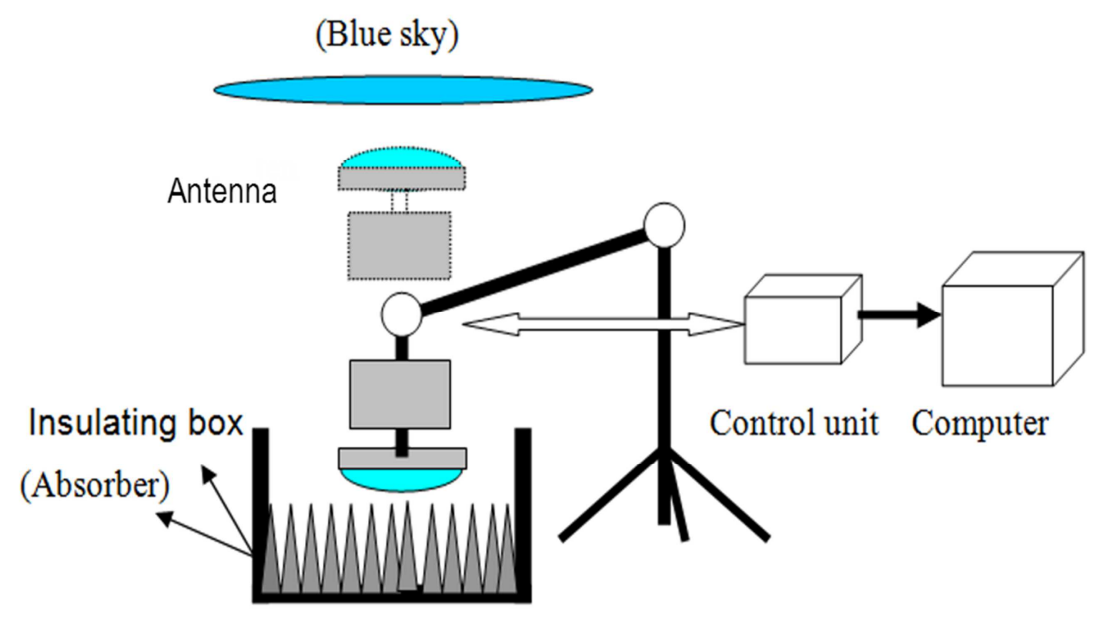

Figure 2. Scheme for calibration of radiometers.

Calibration of the microwave radiometers was performed to determine the exact relationship between the output signal of the microwave radiometers (voltage or frequency) and the brightness temperature of the object. Calibration was done with two special reference materials: the black body (Absorber) represents the "hot standard object", and the blue sky, symbolizing the "cold standard object" (Figure 2). The radiometers were calibrated by measuring the emission of the sky and a high-quality microwave absorber with known physical temperature [2]. 
The microwave radiometers output signal was recorded for about 15 minutes and calculated on average. The output signal $f_{i}$ is converted to the brightness temperature $T_{B}$ by the following formula:

$$
T_{B}=T_{B, s k y}+\frac{T_{B, s k y}-T_{B, a b s}}{f_{s k y}-f_{a b s}}\left(f-f_{s k y}\right)
$$

where $T_{B, a b s}$ is the brightness temperatures of the absorber, $T_{B, \text { sky }}$ is the brightness temperatures of the blue sky and $f, f_{\text {sky }}, f_{\text {abs }}$ are the value of the microwave radiometers signal (frequency) when measuring the canopy, blue sky and the absorber, respectively.

After calibrating the radiometers, the radiometers were installed on the ground being directed upwards through the canopy of the investigated African mahogany trees. The tree canopy as seen from the microwave radiometers position for angles $0^{\circ}, 15^{\circ}, 30^{\circ}, 45^{\circ}$ and $60^{\circ}$ (relative to zenith), in this position downwelling microwave radiation of the canopy was measured.

\subsection{Transmission model of trees canopy using ground-based upward-looking microwave radiometers}

The passive remote sensing method is based on the measurement of the object's brightness temperatures by microwave radiometer, and then application of a physical model to calculate the quantities to be surveyed.

\subsubsection{Brightness temperatures}

This research was applied and developed by the Mätzler model [1], and compared with the model of Vichev et al. [3]. According to Mätzler model, microwave radiometer measured the brightness temperature $T_{B}$ of down welling radiation, which can be expressed by:

$$
T_{B}=t T_{B, s k y}+r T_{B 0}+(1-r-t) T_{V}
$$

where $t$ is the transmissivity and $\mathrm{r}$ is the reflectivity of the vegetation layer. The factor $1-\mathrm{r}-\mathrm{t}$ is the emissivity of the vegetation layer, $\mathrm{T}_{\mathrm{B}, \mathrm{sky}}$ is the brightness temperatures of the blue sky, $\mathrm{T}_{\mathrm{V}}$ is physical temperature of the canopy, $\mathrm{T}_{\mathrm{B} 0}$ is upward brightness temperatures of the ground, $\mathrm{T}_{0}$ is upward physical temperatures of the ground. We can express $r$ and $t$ as:

$$
\begin{aligned}
& r=\frac{T_{B}-T_{V}+t\left(T_{V}-T_{B, s k y}\right)}{\delta T} \\
& t=\frac{T_{V}+r \delta T-T_{B}}{T_{V}-T_{B, s k y}}
\end{aligned}
$$

with the definition of: $\delta T=T_{B 0}-T_{V}$.

According to Mätzler [1], we note that the surface emissivity of the ground below the canopy is near 0.95 over the entire frequency range. Therefore, $T_{B 0}$ approaches $T_{0}$ even if $T_{B}$ is not very close to $T_{0}$. The reflectivity $r$ of the canopy is close to 0.1 . With this value, we can estimate:

$$
r \delta T=0.1\left(T_{0}-T_{V}\right)
$$


Since $\mathrm{T}_{0}$ and $\mathrm{T}_{\mathrm{V}}$ were always very similar (differences were typically within $\pm 2{ }^{\circ} \mathrm{C}$ ), we can neglect rdT in (4) and estimate the transmissivity from the physical temperature of the canopy, the brightness temperatures of the canopy, and the blue sky at the corresponding frequencies by the formula (7).

Vichev et al. presented the concept of normalized brightness temperatures as calculated by the formula [2],

$$
T_{B N}=\frac{T_{B}}{T_{V}}
$$

where $T_{V}$ is physical temperature of the canopy, $T_{B}$ is brightness temperatures.

\subsubsection{Transmissivity}

Transmissivity was calculated by using two different models of Mätzler [1] and Vichev et al. [3], denoted as $t$ and $t_{2}$, respectively. With $t$ is calculated by the formula (7),

$$
t=\frac{T_{V}-T_{B}}{T_{V}-T_{B, s k y}}
$$

$\mathrm{T}_{\mathrm{B}, \mathrm{sky}}$ is the brightness temperatures of the sky.

Brightness temperatures $T_{B}$ were calculated from the output signal of the radiometers that measure trees canopy by the equation (1); where: $T_{B, a b s}$ is the brightness temperatures of the absorber and $\mathrm{f}, \mathrm{f}_{\mathrm{sky}}, \mathrm{f}_{\mathrm{abs}}$ are the value of the microwave radiometers signal (frequency) when measuring the canopy, blue sky and the absorber, respectively.

The sky brightness temperature $\mathrm{T}_{\mathrm{B}, \mathrm{sky}}$ was calculated using the model of Pellarin et al. [4],

$$
T_{B, S k y}(\theta)=T_{B-A T M-D}(\theta)+T_{B-\operatorname{Cos}-D}(\theta)
$$

where $\mathrm{T}_{\mathrm{B}-\mathrm{ATMS}-\mathrm{D}}(\theta)$ and $\mathrm{T}_{\mathrm{B}-\cos -\mathrm{D}}(\theta)$ are the downward atmospheric and cosmic brightness temperatures, respectively.

The downward atmospheric brightness temperature $\mathrm{T}_{\text {B-ATMS-D }}(\theta)$ was calculated as:

$$
\begin{gathered}
T_{B-A T M-D}(\theta)=T_{A T M e q}\left(1-e^{\frac{-\tau_{A T M}}{\cos (\theta)}}\right) \\
\tau_{A T M}=\exp \left(-3.9262-0.2211 Z-0.00369 T_{2 m}\right) \\
T_{A T M e q}=\exp \left(4.9274+0.002195 \mathrm{~T}_{2 \mathrm{~m}}\right)
\end{gathered}
$$

where $\tau_{\mathrm{ATM}}$ and $\mathrm{T}_{\mathrm{ATMeq}}$ are the atmosphere optical thickness and equivalent temperature, $\mathrm{Z}(\mathrm{km})$ is the surface altitude and $\mathrm{T}_{2 \mathrm{~m}}(\mathrm{~K})$ is the air temperature (measured at $2 \mathrm{~m}$ above the ground).

The downward cosmic emission $\mathrm{T}_{\mathrm{B}-\mathrm{COS}-\mathrm{D}}(\theta)$ was calculated as:

where $\mathrm{T}_{\text {cosmos }}=2.7 \mathrm{~K}$.

$$
T_{B-\operatorname{Cos}-D}(\theta)=T_{\operatorname{cosmos}} e^{\frac{-\tau_{A T M}}{\cos (\theta)}}
$$

Using equations proposed by Vichev at al., the transmissivities of the tree crowns were calculated as follows:

$$
t_{2} \approx 1-\mathrm{T}_{\mathrm{BN}}
$$

$\Delta \mathrm{t}$ is the difference between $t$ and $\mathrm{t}_{2}$ and was calculated as:

$$
\Delta t=t-t_{2}
$$


The experiment of Vichev et al. showed that the transmissivities obtained through the two methods of calculation gave similar results with differences $\Delta t \leq 0.01$.

\section{EXPERIMENTALLY MEASURED DATA}

For the purpose of evaluating transmissivity through the trees canopy at microwave frequency band, specifically the $\mathrm{L}$ and $\mathrm{X}$ bands, the research team conducted experiments in October 2015 and July 2016 at the Vietnam Academy of Science and Technology campus in Hanoi. Measurements were made with the L-band radiometer in both horizontal and vertical polarization, while that of $\mathrm{X}$ band radiometer only performed with thevertical polarization. Immediately after the experiment was conducted, the tree and environment parameters were processed.

\subsection{The sky brightness temperature $T_{B, \text { sky }}$}

In the experiment, the blue sky brightness temperature often get approximate values: $\mathrm{T}_{\mathrm{B}, \mathrm{sky}} \approx$ $5 \mathrm{~K}$. However in reality, $\mathrm{T}_{\mathrm{B}, \mathrm{sky}}$ changes with altitude, air temperature, and the viewing angle can be calculated based on the model of Pellarin at al.. In this study, experimental location was fixed so that the height $\mathrm{Z}$ was not changed. Tables 1 and 2 below present the results of the calculation of blue sky brightness temperature for two times in situ measurements.

Table1. Calculation results of $\mathrm{T}_{\mathrm{B}, \mathrm{sky}}$ with $\mathrm{Z}=0.012 \mathrm{~km}$, and $\mathrm{T}_{2 \mathrm{~m}}=300 \mathrm{~K}$.

\begin{tabular}{|c|c|c|c|c|c|}
\hline $\boldsymbol{\theta}$ & $\boldsymbol{\tau}_{\text {ATM }}(\mathbf{K})$ & $\mathbf{T}_{\text {ATMeq }}(\mathbf{K})$ & $\mathbf{T}_{\text {B-ATMS-D }}(\mathbf{K})$ & $\mathbf{T}_{\text {B-COs-D }}(\mathbf{K})$ & $\mathbf{T}_{\text {B,sky }}(\mathbf{K})$ \\
\hline $0^{0}$ & 266.64 & 0.01 & 1.73 & 2.68 & 4.41 \\
\hline $15^{0}$ & 266.64 & 0.01 & 1.79 & 2.68 & 4.47 \\
\hline $30^{0}$ & 266.64 & 0.01 & 1.99 & 2.68 & 4.67 \\
\hline $45^{0}$ & 266.64 & 0.01 & 2.44 & 2.68 & 5.11 \\
\hline $60^{0}$ & 266.64 & 0.01 & 3.44 & 2.67 & 6.11 \\
\hline
\end{tabular}

Table 2. Calculation results of $\mathrm{T}_{\mathrm{B}, \mathrm{kky}}$ with $\mathrm{Z}=0.012 \mathrm{~km}$, and $\mathrm{T}_{2 \mathrm{~m}}=308 \mathrm{~K}$.

\begin{tabular}{|c|c|c|c|c|c|}
\hline $\boldsymbol{\theta}$ & $\boldsymbol{\tau}_{\text {ATM }}(\mathbf{K})$ & $\mathbf{T}_{\text {ATMeq }}(\mathbf{K})$ & $\mathbf{T}_{\text {B-ATMS-D }}(\mathbf{K})$ & $\mathbf{T}_{\text {B-COS-D }}(\mathbf{K})$ & $\mathbf{T}_{\text {B,sky }}(\mathbf{K})$ \\
\hline $0^{0}$ & 271.36 & 0.01 & 1.71 & 2.68 & 4.39 \\
\hline $15^{0}$ & 271.36 & 0.01 & 1.77 & 2.68 & 4.45 \\
\hline $30^{0}$ & 271.36 & 0.01 & 1.97 & 2.68 & 4.65 \\
\hline $45^{0}$ & 271.36 & 0.01 & 2.41 & 2.68 & 5.09 \\
\hline $60^{0}$ & 271.36 & 0.01 & 3.40 & 2.67 & 6.07 \\
\hline
\end{tabular}

\subsection{Brightness temperature of the canopy}


Table 3. Brightness temperature of the canopy when the antenna is oriented towards the outside edge of the garden (measurements on 26/10/2015).

\begin{tabular}{|c|c|c|c|c|c|c|c|}
\hline $\boldsymbol{\theta}$ & $\mathbf{T}_{\text {abs }}(\mathbf{K})$ & $\mathbf{f}_{\text {abs }}(\mathbf{H z})$ & $\mathbf{f}_{\text {sky }}(\mathbf{H z})$ & $\mathbf{T}_{\mathbf{V}}(\mathbf{K})$ & $\mathbf{f}(\mathbf{H z})$ & $\mathbf{T}_{\mathbf{B}, \mathbf{s k y}}(\mathbf{K})$ & $\mathbf{T}_{\mathbf{B}}{ }^{\mathbf{L H}}(\mathbf{K})$ \\
\hline $0^{0}$ & 304.2 & 3400 & 8968 & 303.5 & 6677 & 4.41 & 127.8 \\
\hline $15^{0}$ & 304.2 & 3400 & 8968 & 303.2 & 5762 & 4.47 & 177.1 \\
\hline $30^{0}$ & 304.2 & 3400 & 8968 & 302.4 & 5931 & 4.67 & 168.0 \\
\hline $45^{0}$ & 304.2 & 3400 & 8968 & 301.0 & 6142 & 5.12 & 156.9 \\
\hline $60^{0}$ & 304.2 & 3400 & 8968 & 300.6 & 6017 & 6.11 & 164.1 \\
\hline $\boldsymbol{\theta}$ & $\mathbf{T}_{\text {abs }}(\mathbf{K})$ & $\mathbf{f}_{\text {abs }}(\mathbf{H z})$ & $\mathbf{f}_{\text {sky }}(\mathbf{H z})$ & $\mathbf{T}_{\mathbf{V}}(\mathbf{K})$ & $\mathbf{f}(\mathbf{H z})$ & $\mathbf{T}_{\mathbf{B}, \mathbf{s k y}}(\mathbf{K})$ & $\mathbf{T}_{\mathbf{B}}{ }^{\mathbf{}}(\mathbf{K})$ \\
\hline $0^{0}$ & 304.2 & 3425 & 8735 & 303.5 & 6658 & 4.41 & 121.7 \\
\hline $15^{0}$ & 304.2 & 3425 & 8735 & 303.2 & 5812 & 4.47 & 169.5 \\
\hline $30^{0}$ & 304.2 & 3425 & 8735 & 302.4 & 6082 & 4.67 & 154.3 \\
\hline $45^{0}$ & 304.2 & 3425 & 8735 & 301.0 & 6175 & 5.12 & 149.3 \\
\hline $60^{0}$ & 304.2 & 3425 & 8735 & 300.6 & 6224 & 6.11 & 147.1 \\
\hline $\boldsymbol{\theta}$ & $\mathbf{T}_{\text {abs }}(\mathbf{K})$ & $\mathbf{f}_{\text {abs }}(\mathbf{H z})$ & $\mathbf{f}_{\text {sky }}(\mathbf{H z})$ & $\mathbf{T}_{\mathbf{V}}(\mathbf{K})$ & $\mathbf{f}(\mathbf{H z})$ & $\mathbf{T}_{\mathbf{B}, \text { sky }}(\mathbf{K})$ & $\mathbf{T}_{\mathbf{B}} \mathbf{\mathbf { X V }}(\mathbf{K})$ \\
\hline $0^{0}$ & 304.2 & 3581 & 7255 & 303.5 & 4365 & 4.41 & 240.2 \\
\hline $15^{0}$ & 304.2 & 3581 & 7255 & 303.2 & 4375 & 4.47 & 239.4 \\
\hline $30^{0}$ & 304.2 & 3581 & 7255 & 302.4 & 4408 & 4.67 & 236.8 \\
\hline $45^{0}$ & 304.2 & 3581 & 7255 & 301.0 & 4582 & 5.12 & 222.7 \\
\hline $60^{0}$ & 304.2 & 3581 & 7255 & 300.6 & 4407 & 6.11 & 237.2 \\
\hline
\end{tabular}

Brightness temperature (26/10/2015)

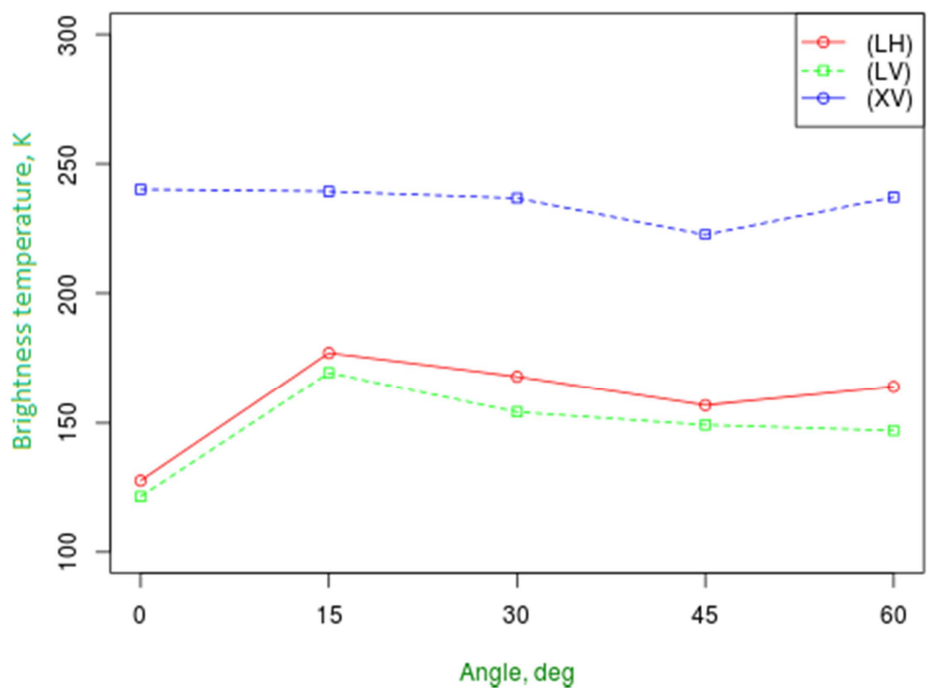

Figure 3. Brightness temperature of the canopy (measurements on 26/10/2015).

Value $T_{B}{ }^{L H}$ in the same condition is often greater than the value $T_{B}{ }^{L V}$ of about $5 \mathrm{~K}$ to $10 \mathrm{~K}$, but $\mathrm{T}_{\mathrm{B}}{ }^{\mathrm{XV}}$ usually get the largest value in the range of $210 \mathrm{~K}$ and $250 \mathrm{~K}$. The difference of the brightness temperature is mainly due to observation angle $\theta$ decision. 
Table 4. Brightness temperature of the canopy when the antenna is oriented towards the middle of the garden (measurements on 16/07/2016).

\begin{tabular}{|c|c|c|c|c|c|c|c|}
\hline $\boldsymbol{\theta}$ & $\mathbf{T}_{\text {abs }}(\mathbf{K})$ & $\mathbf{f}_{\text {abs }}(\mathbf{H z})$ & $\mathbf{f}_{\text {sky }}(\mathbf{H z})$ & $\mathbf{T}_{\mathbf{V}}(\mathbf{K})$ & $\mathbf{f}(\mathbf{H z})$ & $\mathbf{T}_{\mathbf{B}, \text { sky }}(\mathbf{K})$ & $\mathbf{T}_{\mathbf{B}}{ }^{\mathbf{L H}}(\mathbf{K})$ \\
\hline $0^{0}$ & 305.5 & 3470 & 9125 & 306.0 & 6595 & 4.39 & 139.1 \\
\hline $15^{0}$ & 305.5 & 3470 & 9125 & 305.8 & 5776 & 4.45 & 182.7 \\
\hline $30^{0}$ & 305.5 & 3470 & 9125 & 304.5 & 5592 & 4.65 & 192.6 \\
\hline $45^{0}$ & 305.5 & 3470 & 9125 & 303.6 & 5486 & 5.09 & 198.4 \\
\hline $60^{0}$ & 305.5 & 3470 & 9125 & 302.8 & 5264 & 6.07 & 210.5 \\
\hline $\boldsymbol{\theta}$ & $\mathbf{T}_{\text {abs }}(\mathbf{K})$ & $\mathbf{f}_{\text {abs }}(\mathbf{H z})$ & $\mathbf{f}_{\text {sky }}(\mathbf{H z})$ & $\mathbf{T}_{\mathbf{V}}(\mathbf{K})$ & $\mathbf{f}(\mathbf{H z})$ & $\mathbf{T}_{\mathbf{B}, \text { sky }}(\mathbf{K})$ & $\mathbf{T}_{\mathbf{B}}{ }^{\mathbf{L V}}(\mathbf{K})$ \\
\hline $0^{0}$ & 305.5 & 3395 & 9110 & 306.0 & 6607 & 4.39 & 136.3 \\
\hline $15^{0}$ & 305.5 & 3395 & 9110 & 305.8 & 5790 & 4.45 & 179.3 \\
\hline $30^{0}$ & 305.5 & 3395 & 9110 & 304.5 & 5721 & 4.65 & 183.1 \\
\hline $45^{0}$ & 305.5 & 3395 & 9110 & 303.6 & 5597 & 5.09 & 189.8 \\
\hline $60^{0}$ & 305.5 & 3395 & 9110 & 302.8 & 5316 & 6.07 & 204.9 \\
\hline $\boldsymbol{\theta}$ & $\mathbf{T}_{\text {abs }}(\mathbf{K})$ & $\mathbf{f}_{\text {abs }}(\mathbf{H z})$ & $\mathbf{f}_{\text {sky }}(\mathbf{H z})$ & $\mathbf{T}_{\mathbf{V}}(\mathbf{K})$ & $\mathbf{f}(\mathbf{H z})$ & $\mathbf{T}_{\mathbf{B}, \text { sky }}(\mathbf{K})$ & $\mathbf{T}_{\mathbf{B}}{ }^{\mathbf{X V}}(\mathbf{K})$ \\
\hline $0^{0}$ & 305.5 & 2147 & 7296 & 306.0 & 3675 & 4.39 & 216.1 \\
\hline $15^{0}$ & 305.5 & 2147 & 7296 & 305.8 & 3455 & 4.45 & 229.0 \\
\hline $30^{0}$ & 305.5 & 2147 & 7296 & 304.5 & 3406 & 4.65 & 231.9 \\
\hline $45^{0}$ & 305.5 & 2147 & 7296 & 303.6 & 3297 & 5.09 & 238.4 \\
\hline $60^{0}$ & 305.5 & 2147 & 7296 & 302.8 & 3215 & 6.07 & 243.4 \\
\hline
\end{tabular}

Brightness temperature (16/07/2016)

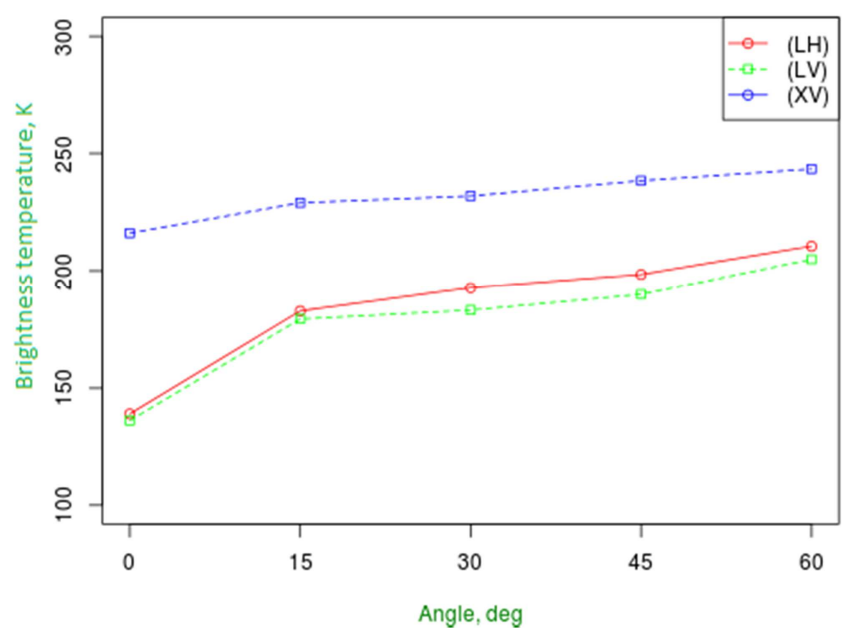

Figure 4. Brightness temperature of the canopy (measurements on 16/07/2016).

Normally, when the antenna is oriented towards the middle of the garden to measure brightness temperature of trees canopy, the minimum value of brightness temperature will be corresponding to the observed vertical direction. When lowering the observation direction, that means the angle between the antenna axis and the vertical direction $\theta$ increases, all of the value $\mathrm{T}_{\mathrm{B}}{ }^{\mathrm{LH}}, \mathrm{T}_{\mathrm{B}}{ }^{\mathrm{LV}}, \mathrm{T}_{\mathrm{B}}{ }^{\mathrm{XV}}$ tend to increase. 


\subsection{Transmissivity of the canopy}

Table 5. Transmissivity of the canopy when the antenna is oriented towards the outside edge of the garden (measurements on 26/10/2015).

\begin{tabular}{|c|c|c|c|c|c|c|c|}
\hline $\boldsymbol{\theta}$ & $\mathbf{T}_{\mathbf{V}}(\mathbf{K})$ & $\mathbf{T}_{\mathbf{B}, \mathbf{s k y}}(\mathbf{K})$ & $\mathbf{T}_{\mathbf{B}}(\mathbf{K})$ & $\mathbf{t}^{\mathbf{L H}}$ & $\mathbf{T}_{\mathbf{B N}}$ & $\mathbf{t}_{\mathbf{2}}^{\mathbf{L H}}$ & $\boldsymbol{\Delta ~}^{\mathbf{L H}}$ \\
\hline $0^{0}$ & 303.5 & 4.4 & 127.8 & 0.588 & 0.421 & 0.579 & 0.009 \\
\hline $15^{0}$ & 303.2 & 4.5 & 177.1 & 0.422 & 0.584 & 0.416 & 0.006 \\
\hline $30^{0}$ & 302.4 & 4.7 & 168.0 & 0.451 & 0.556 & 0.444 & 0.007 \\
\hline $45^{0}$ & 301.0 & 5.1 & 156.9 & 0.487 & 0.521 & 0.479 & 0.008 \\
\hline $60^{0}$ & 300.6 & 6.1 & 164.1 & 0.464 & 0.546 & 0.454 & 0.009 \\
\hline $\boldsymbol{\theta}$ & $\mathbf{T}_{\mathbf{V}}(\mathbf{K})$ & $\mathbf{T}_{\mathbf{B}, \mathbf{s k y}}(\mathbf{K})$ & $\mathbf{T}_{\mathbf{B}}(\mathbf{K})$ & $\mathbf{t}^{\mathbf{L V}}$ & $\mathbf{T}_{\mathbf{B N}}$ & $\mathbf{t}_{\mathbf{2}}^{\mathbf{L V}}$ & $\boldsymbol{\Delta} \mathbf{t}^{\mathbf{L V}}$ \\
\hline $0^{0}$ & 303.5 & 4.4 & 121.7 & 0.608 & 0.401 & 0.599 & 0.009 \\
\hline $15^{0}$ & 303.2 & 4.5 & 169.5 & 0.448 & 0.559 & 0.441 & 0.007 \\
\hline $30^{0}$ & 302.4 & 4.7 & 154.3 & 0.497 & 0.510 & 0.490 & 0.008 \\
\hline $45^{0}$ & 301.0 & 5.1 & 149.3 & 0.513 & 0.496 & 0.504 & 0.009 \\
\hline $60^{0}$ & 300.6 & 6.1 & 147.1 & 0.521 & 0.489 & 0.511 & 0.011 \\
\hline $\boldsymbol{\theta}$ & $\mathbf{T}_{\mathbf{V}}(\mathbf{K})$ & $\mathbf{T}_{\mathbf{B}, \mathbf{s k y}}(\mathbf{K})$ & $\mathbf{T}_{\mathbf{B}}(\mathbf{K})$ & $\mathbf{t}^{\mathbf{X V}}$ & $\mathbf{T}_{\mathbf{B N}}$ & $\mathbf{t}_{\mathbf{2}}^{\mathbf{X V}}$ & $\mathbf{\Delta} \mathbf{t}^{\mathbf{X V}}$ \\
\hline $0^{0}$ & 303.5 & 4.41 & 240.2 & 0.212 & 0.792 & 0.208 & 0.003 \\
\hline $15^{0}$ & 303.2 & 4.47 & 239.4 & 0.213 & 0.790 & 0.210 & 0.003 \\
\hline $30^{0}$ & 302.4 & 4.67 & 236.8 & 0.220 & 0.783 & 0.217 & 0.003 \\
\hline $45^{0}$ & 301.0 & 5.12 & 222.7 & 0.265 & 0.740 & 0.260 & 0.005 \\
\hline $60^{0}$ & 300.6 & 6.11 & 237.2 & 0.215 & 0.789 & 0.211 & 0.004 \\
\hline
\end{tabular}

where $\mathbf{T}_{\mathbf{B N}}, \mathbf{t}^{\mathbf{X v}}, \mathbf{t}_{\mathbf{2}}{ }^{\mathbf{X v}}$ and $\Delta \mathbf{t}^{\mathbf{X v}}$ are a non-unit coefficient.

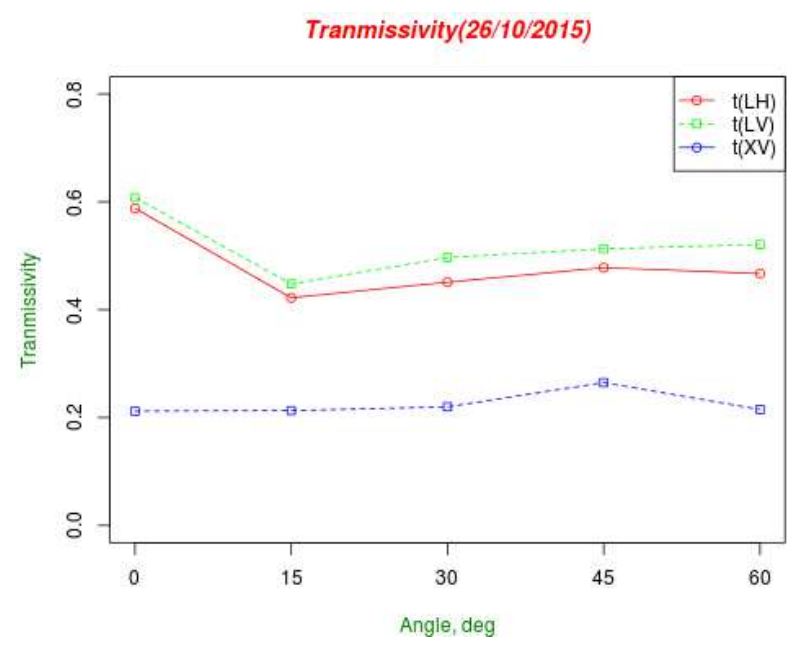

Figure 5. Transmissivity of the canopy (measurements on 26/10/2015).

In all experimental phases, $\mathrm{t}^{\mathrm{LH}}$ and $\mathrm{t}^{\mathrm{LV}}$ at $\theta=0^{0}$ get the maximum value ranges from 0.55 to 0.6. When the antenna of the radiometers is oriented towards the outside edge of the garden, 
changing of the angle $\theta$ does not significally influence the transmissivity of L-band at both polarization. But when the antenna is oriented towards the middle of the garden, transmissivity of L-band at both polarization significantly reduced while increasing the angle $\theta \cdot \mathrm{t}^{\mathrm{LH}}$ and $\mathrm{t}^{\mathrm{LV}}$ value at the angle $\theta=60^{\circ}$ only between 0.31 to 0.33 showed that the leaves have little impact to transmissivity of L-Band.

Table 6. Transmissivity of the canopy when the antenna is oriented towards the middle of the garden (measurements on 16/07/2016).

\begin{tabular}{|c|c|c|c|c|c|c|c|}
\hline $\boldsymbol{\theta}$ & $\mathbf{T}_{\mathbf{V}}(\mathbf{K})$ & $\mathbf{T}_{\mathbf{B}, \mathbf{s k y}}(\mathbf{K})$ & $\mathbf{T}_{\mathbf{B}}(\mathbf{K})$ & $\mathbf{t}^{\mathbf{L H}}$ & $\mathbf{T}_{\mathbf{B N}}$ & $\mathbf{t}_{\mathbf{2}}^{\mathbf{L H}}$ & $\Delta \mathbf{t}^{\mathbf{L H}}$ \\
\hline $0^{0}$ & 306.0 & 4.39 & 139.1 & 0.553 & 0.455 & 0.545 & 0.008 \\
\hline $15^{0}$ & 305.8 & 4.45 & 182.7 & 0.408 & 0.598 & 0.402 & 0.006 \\
\hline $30^{0}$ & 304.5 & 4.65 & 192.6 & 0.373 & 0.633 & 0.367 & 0.006 \\
\hline $45^{0}$ & 303.6 & 5.09 & 198.4 & 0.352 & 0.654 & 0.346 & 0.006 \\
\hline $60^{0}$ & 302.8 & 6.07 & 210.5 & 0.311 & 0.695 & 0.305 & 0.006 \\
\hline $\boldsymbol{\theta}$ & $\mathbf{T}_{\mathbf{V}}(\mathbf{K})$ & $\mathbf{T}_{\mathbf{B}, \mathbf{s k y}}(\mathbf{K})$ & $\mathbf{T}_{\mathbf{B}}(\mathbf{K})$ & $\mathbf{t}^{\mathbf{L V}}$ & $\mathbf{T}_{\mathbf{B N}}$ & $\mathbf{t}_{\mathbf{2}}{ }^{\mathbf{L V}}$ & $\boldsymbol{\Delta} \mathbf{t}^{\mathbf{L V}}$ \\
\hline $0^{0}$ & 306.0 & 4.39 & 136.3 & 0.563 & 0.445 & 0.555 & 0.008 \\
\hline $15^{0}$ & 305.8 & 4.45 & 179.3 & 0.420 & 0.586 & 0.414 & 0.006 \\
\hline $30^{0}$ & 304.5 & 4.65 & 183.1 & 0.405 & 0.601 & 0.399 & 0.006 \\
\hline $45^{0}$ & 303.6 & 5.09 & 189.8 & 0.381 & 0.625 & 0.375 & 0.006 \\
\hline $60^{0}$ & 302.8 & 6.07 & 204.9 & 0.330 & 0.677 & 0.323 & 0.007 \\
\hline $\boldsymbol{\theta}$ & $\mathbf{T}_{\mathbf{V}}(\mathbf{K})$ & $\mathbf{T}_{\mathbf{B}, \mathbf{s k y}}(\mathbf{K})$ & $\mathbf{T}_{\mathbf{B}}(\mathbf{K})$ & $\mathbf{t}^{\mathbf{X V}}$ & $\mathbf{T}_{\mathbf{B N}}$ & $\mathbf{t}_{2} \mathbf{X V}^{\mathbf{X V}}$ & $\boldsymbol{\Delta} \mathbf{t}^{\mathbf{X V}}$ \\
\hline $0^{0}$ & 306.0 & 4.39 & 216.1 & 0.298 & 0.706 & 0.294 & 0.004 \\
\hline $15^{0}$ & 305.8 & 4.45 & 229.0 & 0.255 & 0.749 & 0.251 & 0.004 \\
\hline $30^{0}$ & 304.5 & 4.65 & 231.9 & 0.242 & 0.762 & 0.238 & 0.004 \\
\hline $45^{0}$ & 303.6 & 5.09 & 238.4 & 0.218 & 0.785 & 0.215 & 0.004 \\
\hline $60^{0}$ & 302.8 & 6.07 & 243.4 & 0.200 & 0.804 & 0.196 & 0.004 \\
\hline
\end{tabular}

Tranmissivity(16/07/2016)

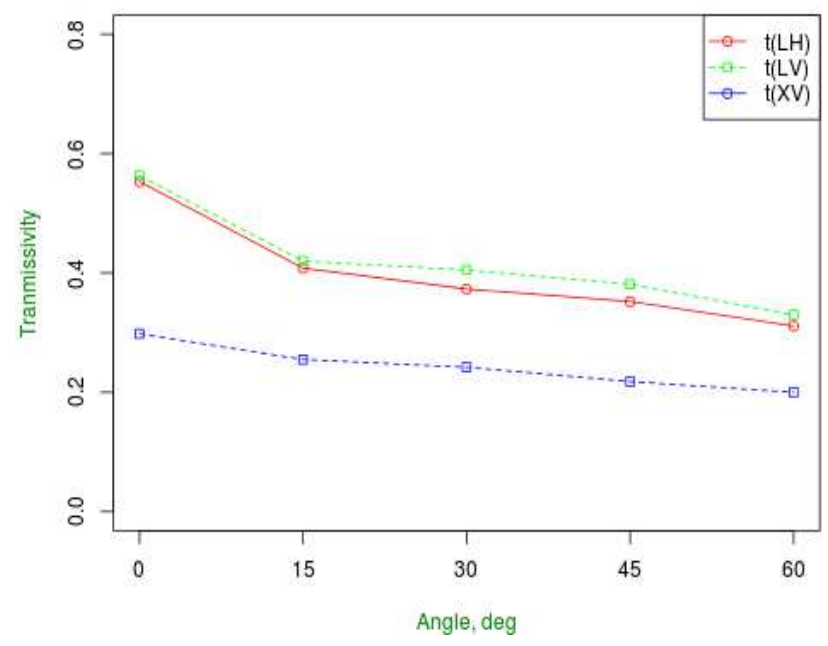

Figure 6. Transmissivity of the canopy (measurements on 16/07/2016). 


\section{DISCUSSION}

In this experiment, the brightness temperatures $T_{B}$ and $T_{B N}$ corresponding to L-band measurements, do not depend much on the angle of view. According to Vichev et al. [3], the standard brightness temperature $\mathrm{T}_{\mathrm{BN}}$ and its variations in space and time depend on: branch mass and volume, water content, leaf biomass andwater content and temperature. The transmissivity of L-band, as shown in Table $1, \mathrm{t}^{\mathrm{LH}}$ and $\mathrm{t}^{\mathrm{LV}}$ at angles $\theta=0^{0}$ are values ranging from 0.55 to 0.6 , has similar results with those by some authors $[3,5,6]$ and [7] and confirms that the canopy is semi-transparent. The error of transmissivity is estimated to be less than 0.01 for the values of $\mathrm{T}_{\mathrm{B}}$, which is quite reasonable as compared with reported data.

The transmissivity is defined by two different methods. Mätzler's model estimates the transmissivity from the physical temperature of the canopy, the brightness temperature of the canopy, and the blue sky at the corresponding frequencies through equation (6). The model by Vichev et al. used equations (13) to estimate the transmissivity from the physical temperature of the canopy and the brightness temperature of the canopy. Although the two methods have many differences, the results obtained by their application do not differ much each from the other. Experimentation has shown that the difference of the transmissivity obtained through two calculation methods is usually of $\Delta t \leq 0.01$.

Transmissivity of $L$ band with both horizontal and vertical polarization at $0^{0}$ get value bigger at than that at $60^{\circ}$. The brightness temperature of the canopy measured by the $L$ band at the angles varies markedly in both polarizations, which demonstrates that $L$ band is relatively large polarization. Transmissivity in the vertical direction is larger than that in the horizontal direction, which is easy to explain because transmissivity depends on the characteristics of vertical growth trees.

The quantitative observations showed that the trunk was a dependent source of L-band radiation, which is consistent with the predictiion by the model of microwave radiation transmitted through trees canopy. The comparison of transmissivity shows that the transmissivity $L$ band is less affected by the leaves of the tree. The transmissivity comparison between $\mathrm{H}$ and $\mathrm{V}$ polarization reveals the small contribution of the trunk to the total absorption of the canopy. From these observations, it can be concluded that tree branches play a major role in the absorption of L-band radiation propagated through the canopy.

Experimental results showed that the brightness temperature of a canopy at a fixed position does not differ much at different times of measurement, exept for significant changes in weather. Because the research object is the foliage of the khaya senegalensis canopies that has matured, the state of foliage changed not much during the study period. $\mathrm{T}_{\mathrm{B}}{ }^{\mathrm{LH}}$ mainly reached values in the range of $120 \mathrm{~K}$ to $200 \mathrm{~K}$. The value of $\mathrm{T}_{\mathrm{B}}^{\mathrm{LH}}$ at the same test conditions are usually larger than $\mathrm{T}_{\mathrm{B}}^{\mathrm{LV}}$ values of about $5 \mathrm{~K}$ to $10 \mathrm{~K}$ but the values of $\mathrm{T}_{\mathrm{B}}{ }^{\mathrm{XV}}$ are usually greatest and range from 210 $\mathrm{K}$ to $250 \mathrm{~K}$. The difference of brightness temperatures is mainly due to the angle of observation $\theta$ decision. Typically, the antenna of the radiometer is directed towards the center of the the khaya senegalensis canopy to measure the brightness temperatures of the canopy, the minimum value of the brightness temperatures will correspond to the vertical upward direction. Lowering the viewing angle means that the angle between the axis of the antenna and the vertical axis $\theta$ increases, the values of $\mathrm{T}_{B}{ }^{\mathrm{LH}}, \mathrm{T}_{\mathrm{B}}{ }^{\mathrm{LV}}, \mathrm{T}_{\mathrm{B}}{ }^{\mathrm{XV}}$ tend to increase. This is understandable because when $\theta=0^{0}$, the radiometer is directed towards the "cold standard object" i.e.the blue sky. The vertical direction is also through the thinnest canopy if the distance from the test site to the edge of the canopy is much larger than the height of the canopy. During the experiment on October 26, 2015, the antenna of the radiometer was pointed to the outer edge of the khaya senegalensis 
canopy, at this measurement direction, the radiometer were disturbed by other objects outside the canopy so the results were not as accurate as in the case of the antenna of the radiometer is directed towards the center of the the khaya senegalensis canopy. Although the opening angle of the radiometers antenna was relatively large (the $\mathrm{L}$ band is $32^{\circ}$ and the $\mathrm{X}$ band is $17^{\circ}$ ), but due to the large differences in the viewing angles of $0^{\circ}, 15^{\circ}, 30^{\circ}, 45^{\circ}, 60^{\circ}$, the results of the measurements differed significantly.

In all experiments, $t^{\mathrm{LH}}$ and $t^{\mathrm{LV}}$ at angles $\theta=0^{0}$ have the greatest values from 0.55 to 0.6 . When the antenna of the radiometer is directed to the outermost edge of the khaya senegalensis canopies, changing the angle $\theta$ does not significantly affect the transmissivity of the L-band radiometer at any polarizations. But as the antenna of the radiometer is pointed toward the center of the khaya senegalensis canopies, the transmissivity of the L-band radiometer at both polarizations decreases markedly by increasing the angle $\theta$. The value of $\mathrm{t}^{\mathrm{LH}}$ and $\mathrm{t}^{\mathrm{LV}}$ at the angle $\theta=60^{\circ}$ is only 0.31 to 0.33 . This suggests that the leaves have little effect on the transmissivity of the L-band radiometer. Furthermore, there is a difference in the transmissivity between the two polarizations of the L-band when lowering the viewing angle to show that the branches and trunks play a major role in L-band radiation absorption. The X-band transmissivity always get a low value of 0.2 to 0.3 and there is no noticeable change in changing the viewing angle $\theta$. So it can be deduced that the leaves have a role of absorbing X_band radiation much larger than those of L-band. From the above quantitative results it can be shown that the canopy is an opaque medium with X-band frequency but semi-transparent medium for L_band. This finding is consistent with the results of other studies reported e.g. in [5 - 10]. This preliminary study has demonstrated the characteristics of L-band and X-band transmission in tree canopy based on both modelling and empirical data.

\section{CONCLUSION}

Based on the field measurement campaign in 2015 and 2016, performed by using groundbased upward-looking microwave radiometers in $\mathrm{L}$ band and $\mathrm{X}$ band microwave transmissivities of khaya senegalensis canopies the brightness temperatures and the transmissivity of the canopy have been calculated and discussed.

These results provide empirical evidence to quantify the characteristics of microwave which is transmitted in the canopy to support the the analysis and assessment of corresponding data obtained when the device is set high above and measuring downwards to the canopy.

Acknowledgements. The above research was conducted in the framework of the project "Investigation of tree crowns and forest canopies in Vietnam using ground-based upward-looking microwave radiometers" in 2015-2016 under code: VAST.HTQT.Bungaria.04/15-16.

\section{REFERENCES}

1. Mätzler C. - Microwave transmissivity of a forest canopy: experiments made with a beech, Remote Sensing of Environment 48 (1994)172-180.

2. Doan Minh Chung - Microwave Emission and Backscattering from the flooding vegetation as mangroves - Report Publ. Conf. Communication, Electronic and Computer Systems, 15-17 ${ }^{\text {th }}$, May 1997, Sofia, Bulgaria, Vol. 4, 1997, pp.124-126. 
3. Vichev B. I., Krasteva E. N., and Kostov K. G. - Study of seasonal evolution of tree emission using zenith-looking microwave radiometers, in Proc. IGARSS '95, Florence, Italy 2 (1995) 981-983.

4. Pellarin T., Wigneron J. P., Calvet J. C., Berger M., Douville H., Ferrazzoli P., Kerr Y., Lopez-Baeza E., Pulliainen J., Simmonds L. P. - Waldteufel - Two-year global simulation of L-band brightness temperatures over land, IEEE Trans., Geosci. Remote Sensing, (2003) 2135-2139

5. Kostov K. G. and Vichev B. I. - Passive microwave remote sensing of soils and vegetation - Experimental and modeling results (Invited lecture), in Proc. NATO Advanced Research Workshop on Microwave Physics and Technique, Sozopol, Bulgaria, 30.09-05.10.1996, Eds. Horst Groll and Ivan Nedkov, NATO ASI Series High Technology 33 (1997) 251-266.

6. Guglielmetti M., Schwank M., Mätzler C., Oberdörster C., Vanderborght J., and Flühler H. - Measured microwave radiative transfer properties of a deciduous forest canopy, Remote Sensing of Environment 109 (2007) 523-532.

7. Vichev B. I., Krasteva E. N., and Kostov K. G. - Study of seasonal evolution of tree emission using zenith-looking microwave radiometers, in Proc. IGARSS '95, Florence, Italy 2 (1995) 981-983.

8. Ferrazzoli P., Guerriero L., Wigneron J. P. - Simulating L-band emission of forests in view of future satellite applications. IEEE Transactions on Geoscience and Remote Sensing 40 (12) (2002) 2700-2708.

9. Hallikainen M. T., Jolma P. A., Hyyppa J. M. - Satellite microwave radiometry of forest and surface types in Finland. IEEE Transactions on Geoscience and Remote Sensing 26 (5) (1988) 622-628.

10. Santi E., Paloscia S., Pampaloni P., and Pettinato S. - Ground-based microwave investigations of forest plots in Italy, IEEE Trans. Geosci. Remote Sensing, 47 (9) (2009) 3016-3025. 